\title{
Identificação de Danos em Fachadas de Edificações: Geração de Mosaicos Fotográficos Obtidos por Plataforma Robótica
}

\author{
Identification of Damage on Facades of Buildings: Generating Mosaics Photographic Obtained by \\ Robotics Platform
}

\author{
Márcia Silvano Costa \\ Universidade de Brasília, Brasil \\ Marcias_costa@Yahoo.com.br \\ Evangelos D. Christakou \\ Universidade de Brasília, Brasil \\ vangelis@unb.br
}

\author{
Lenildo S. Da Silva \\ Universidade de Brasília, Brasil \\ lenildo@unb.br \\ Antônio A. Nepomuceno \\ Universidade de Brasília, Brasil \\ nepomuceno@unb.br
}

\begin{abstract}
Damage in façades rendering is a problem that has been much discussed currently since such damage is important to the degradation process of building. There are many techniques to verify damages in façades and in other external parts of buildings; however, some tecniques have restrictions regarding their practical applications. This work deals with the application of the remote sensing (RM) technique. Such technique derives from the need to identify, locate and scale, quickly, accurately and without human risk, the existing damage or potential damages that may appear in the façades of buildings. Moreover, the RM technique may help to detect damages not visible at long distance or in location of difficult access. This technique is performed by corrected high-resolution panoramic images generated from a mosaic of pictures taken with a standard digital camera coupled in a robotic platform. The Itamaraty Palace, a government building, located in Brasília - DF (Brazil), is the object of the present study. The correction of the Itamaraty Palace panoramic image was carried out so that the identification, quantification and mapping of the Palace façade damages were performed using specific softwares such as GigaPan Stitch, AutoCAD and ArcGIS.
\end{abstract}

Keywords: Pathologies of buildings; Panoramic mosaics; Robotics platform; Photos rectified and ArcGis.

\section{Introdução}

As fachadas são elementos importantes por fazerem a transição entre os meios exterior e interior de uma edificação, além de contribuírem para o seu comportamento em uso, sob a ação de esforços e das condições do meio ambiente, durante toda a sua vida útil. As patologias que surgem nos sistemas de revestimento de fachadas e faces externas de edificações causam grande impacto negativo, tanto para a integridade física dos usuários como para a construtora, uma vez que as ocorrências dessas manifestações patológicas podem ocasionar elevados prejuízos financeiros e, as causas dessas patologias normalmente envolvem diversos fatores complexos e de difícil diagnóstico.

Normalmente, os métodos preventivos usados para a detecção de danos em fachadas de edificações, estão fundamentados em informações coletadas em campo através de inspeções diretas sobre a edificação, as quais, dependendo do local e da dimensão da edificação, podem implicar em custos elevados de execução e em sério risco de acidente humano. Algumas edificações, como as de grande porte, por exemplo, possuem locais de difícil acesso, tornando ainda mais complexos a inspeção e o gerenciamento de eventuais pontos de degradação.
Como requisito de durabilidade, segundo a norma ABNT NBR 5674, a edificação deve manter a capacidade funcional durante toda a sua vida útil prevista em projeto, desde que as intervenções periódicas de manutenção e de conservação sejam rigorosamente realizadas. Neste sentido, é importante desenvolver meios rápidos, funcionais e capazes de identificar, localizar e dimensionar os danos que ocorrem em uma fase inicial nas fachadas das edificações.

Sendo assim, uma alternativa eficiente para se fazer a inspeção e identificar os danos existentes, ou que possam vir a existir, na superfície externa das fachadas de uma edificação, é a adoção de sistemas de Monitoramento Remoto (MR). Este sistema baseia-se na Fotogrametria Digital, o qual permite analisar e documentar, com segurança e continuidade através de softwares e croquis, remotamente (em um escritório), os danos existentes nas superfícies externas das fachadas de edificações, assim como os danos existentes em locais de difícil acesso, sem a necessidade do contato direto sobre a edificação, de forma eficaz, o que reduz o tempo necessário para o levantamento em campo visando futuras intervenções de manutenção. 
A Fotogrametria é definida como "a ciência e tecnologia de obtenção de informações métricas e não métricas de um determinado objeto ou lugar, por meio de fotografias sem que haja contato físico com o operador", de modo a se determinar as características geométricas do objeto fotografado, tais como: forma, dimensão e posição, (MARCHETTI, 1977). Assim, a fotogrametria é uma técnica fundamentada em fotografias capaz de produzir um documento autêntico e que consegue resgatar a forma exata da edificação, sendo referência para se observar a ocorrência de degradações dos materiais e o andamento de deformações estruturais.

Assim, esta metodologia está baseada no monitoramento remoto dos danos através de imagens panorâmicas de alta resolução (GigaPixel), as quais são geradas a partir de mosaicos fotográficos criados por meio de uma câmera fotográfica digital padrão, acoplada em uma plataforma robótica e processada pelo software ArcGis.

A aplicação desta técnica apresenta uma série de vantagens com relação às formas tradicionais de levantamento, como custo, rapidez, precisão e variedade de produtos que podem ser obtidos, a representação e o registro das edificações a serem estudadas, bem como a avaliação de sua geometria, grandezas lineares, cor e texturas, que são dados essenciais ao planejamento de restauro e avaliação do estado atual de conservação (AMORIM; BASTIAN, 2012).

As vantagens da utilização desta técnica, na documentação de objetos, aumentam ainda mais nos casos de edificações complexas e de grandes dimensões, onde é difícil e trabalhoso o cadastramento através dos métodos tradicionais. Muitas vezes, o estado de deterioração e a presença de pontos inacessíveis em edificações de grande porte tornam-se obstáculos para uma documentação satisfatória (CÓRDOBA, 2012).

Com o uso da Fotogrametria obtêm-se informações confiáveis por meio de processos de captura, interpretação e mensuração das imagens, além de registrar com fidelidade as deformações e patologias dos objetos registrados nas imagens originais. São gerados modelos de alta qualidade para análise, arquivamento e reprodução em diversos tipos de publicações e distribuição por meios eletrônicos.

O objetivo deste trabalho é a identificação rápida e medições precisas dos danos existentes, e que possam vir a ocorrer nas superfícies das fachadas de edificações, de forma a facilitar intervenções eficientes, e avaliação do estado atual de conservação da edificação. Para tanto, foram utilizados equipamentos de alta precisão, capazes de gerar imagens de alta resolução (GigaPixel), tais como: a câmera digital padrão de alta resolução, plataforma robótica, softwares específicos para a geração de mosaicos panorâmicos, assim como softwares necessários para a identificação, quantificação e mapeamento das patologias.
Imagens panorâmicas GigaPixel são imagens de imensa complexidade e, por isso, é necessário criar caminhos possíveis e ideais para visualiza-los e usá-los, tais como a retificação da imagem (SCHORR, 2010).

A Figura 1 mostra duas imagens do Palácio Itamaraty que foram geradas na mesma época e do mesmo ponto de tomada fotográfica, sendo que: a primeira imagem é uma fotografia regular (comum), a qual foi criada através da câmera digital NIKON D700 e objetiva de $20 \mathrm{~mm}$ e serviu como objeto de estudo do mestrado realizado por Cordoba (2012), na Universidade de Brasília - UnB; e a segunda, é um mosaico panorâmico de alta resolução (GigaPixel), criada por Christakou (2012) em trabalho não publicado, a qual foi gerada através da câmera digital Canon EOS Rebel T3i com objetiva $135 \mathrm{~mm}$, acoplada à uma plataforma robótica.

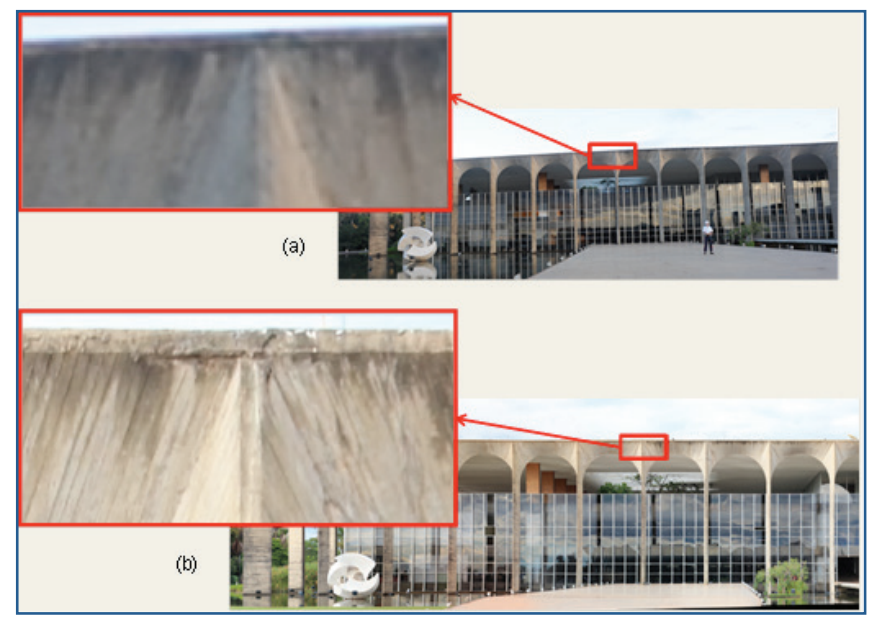

Figura 1: Comparação entre duas imagens do Palácio Itamaraty, Brasília, DF: (a) Imagem regular (comum) e, (b) Imagem panorâmica gerada pela plataforma robótica. Fonte: Cordoba (2012) e Christakou (2012). (CostaMS-01.jpg)

Pela comparação entre as duas imagens é possível observar que: conforme a imagem regular (fotografia única), mesmo sendo de alta resolução, não tem o poder de representar com detalhes, as possíveis patologias existentes na superfície da fachada, justamente por não possuir o mesmo nível de resolução de uma imagem panorâmica gerada por várias fotos.

As imagens panorâmicas são geradas por softwares especializados através da composição de várias fotos individuais, que são capturadas por câmera digital acoplada em uma plataforma robótica, a qual proporciona um deslocamento preciso, tanto no eixo horizontal quanto no vertical.

Quando realizadas por uma mesma câmera, as imagens panorâmicas possuem resolução superior à imagem regular (foto única), justamente por ser o resultado da composição de várias fotos de alta resolução, ou seja, a imagem panorâmica (múltiplas fotos) potencializa a resolução de uma imagem única. Sendo assim, as imagens panorâmicas proporcionam maior facilidade e nitidez ao procedimento de identificação de patologias em fachadas de construções civis, o que justifica o uso desta 
metodologia como uma excelente ferramenta para direcionar as inspeções "in loco" e promover as futuras intervenções de manutenção.

O "PIXEL" é a unidade de mensuração da qualidade das operações fotogramétricas. De acordo com os cálculos elaborados, a resolução do panorama deve ter precisão mínima aproximada, em milímetros, para o tamanho de um pixel, para atender os requisitos de avaliação de danos. Por exemplo, para uma fissura, o tamanho do pixel deverá ser menor do que $0,5 \mathrm{~mm}$, pois, quanto menor o tamanho do pixel, melhor será a precisão.

\section{Metodologia}

O objeto de estudo utilizado para este trabalho foi o Palácio Itamaraty, situado na cidade de Brasília, DF, Brasil, por ser uma obra emblemática da arquitetura e engenharia brasileira do século $X X$, concebida pelo arquiteto Oscar Niemeyer quem projetou uma estrutura prismática composta de pilares com arcos perfeitos reunindo plena harmonia entre volumes, espaços e formas, pelo que deve ser objeto de cuidados especiais que visem salvaguardar o patrimônio monumental com suas características originais.

Os equipamentos utilizados no desenvolvimento do trabalho foram: uma Plataforma Robótica (GigaPan EPIC PRO - EP), onde foi acoplada a Câmera Digital Nikon D700 - FX, com sensor full frame, $12 \mathrm{MP}$, e lente objetiva Nikon 300mm (AF-S Nikkor f/4D ED-IF). A costura dos fotogramas para gerar o mosaico panorâmico foi realizada pelo software Gigapan Stitch e, a retificação da imagem final, assim como a identificação, dimensionamento e mapeamento das áreas degradadas, foram realizados com a utilização do Software ArcGIS.

A plataforma robótica é um tipo de suporte robótico que serve para controlar a câmera fotográfica para a captura de múltiplas imagens e que, a partir de um ponto inicial e um ponto final, indicados pelo operador, direciona os passos e define quantos fotogramas a câmera, nela acoplada, terá que registrar para formar o mosaico panorâmico.

Mais detalhadamente, funciona da seguinte forma: o operador define, através da indicação de um ponto superior à esquerda e um ponto inferior à direita do objeto a ser investigado, a latitude e longitude da área a ser fotografada, assim como, o percentual de sobreposição desejado entre as imagens. Diante destas informações, a plataforma robótica calcula quantas fotos serão necessárias para formar o mosaico panorâmico, o tempo necessário para se obter este número de fotos e como essas fotos serão distribuídas entre linhas e colunas.

Depois de obtidas as fotos, estas são importadas para o software escolhido onde serão "costuradas" (unidas) compondo o panorama. A Figura 2 apresenta um exemplo de como uma imagem panorâmica é formada a partir de um mosaico panorâmico pelo software GigaPan Stitch.

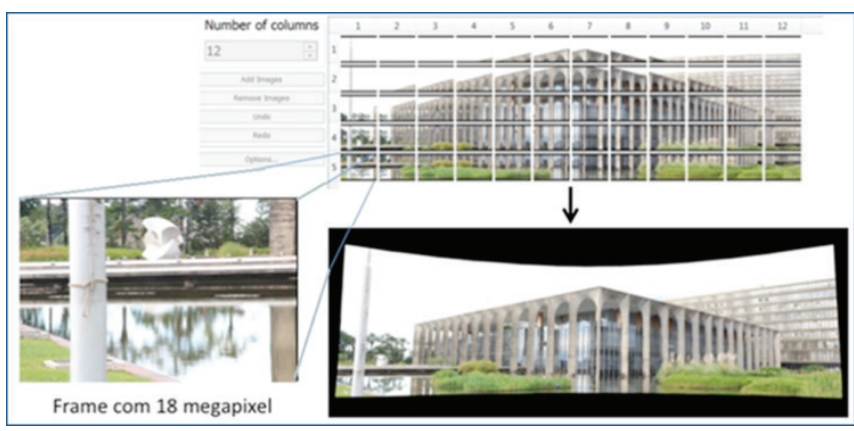

Figura 2: Como as fotos são distribuídas entre linhas e colunas, formando um mosaico panorâmico e, após serem "costuradas", formam uma imagem panoramica. Fonte: Christakou (2012). (Costa-MS-02.jpg)

Ao formar a imagem panorâmica, esta é exportada para o software ArcGis onde é retificada através de pontos de referencia identificados a partir do projeto arquitetônico do objeto em estudo. A retificação da imagem panorâmica é necessária para garantir que o dimensionamento das patologias e as posições no espaço a serem calculadas pelo programa, sejam precisos e reais.

Neste trabalho, foi utilizado o projeto arquitetônico do Palácio Itamaraty e, através do software AutoCAD 2012, foi possível identificar e marcar os principais pontos de referência necessários ao dimensionamento da fachada principal. A Figura 3 apresenta o projeto arquitetônico com os principais pontos de referência que foram marcados e numerados em um total de 30 pontos, os quais são necessários para permitir que a imagem panorâmica fique exatamente proporcional às dimensões determinadas.

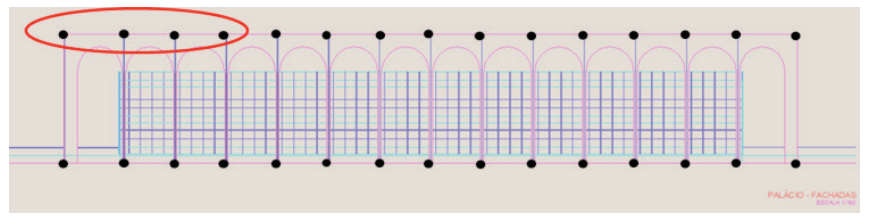

Figura 3: Desenho da fachada principal do Palácio Itamaraty (AutoCAD 2012) com os principais pontos de referência, marcados, necessários para a retificação da imagem panorâmica do Palácio. (Costa-MS-03.jpg)

A Figura 4 apresenta a imagem panorâmica do Palácio, antes da retificação, sendo referenciada pelos principais pontos determinados através do projeto arquitetônico e, posteriormente, a imagem já retificada.

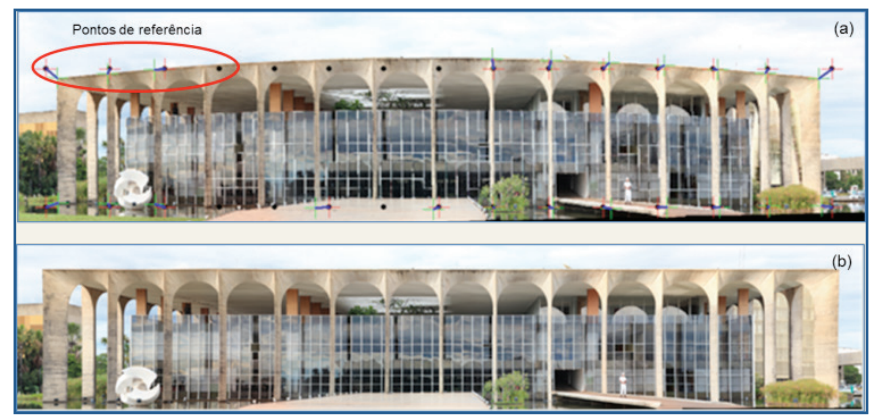

Figura 4: Imagem Panorâmica do Palácio Itamaraty, Brasília, DF: (a) Antes da retificação e, (b) Após a retificação. (Costa-MS-04.jpg) 
Após a imagem ser retificada, foi iniciado o processo de identificação das patologias existentes na superfície externa da fachada principal do Palácio, assim como, também foi possível fazer o mapeamento e o dimensionamento das patologias, com segurança e confiabilidade.

A identificação das patologias foi possível através da aproximação da imagem, pelo software ArcGis, o que permitiu visualizar e delimitar a área atingida de cada tipo de patologia encontrada.

\section{Resultados e Análise}

O mapeamento das patologias identificadas na superfície externa da fachada principal do Palácio Itamaraty foi feito através da delimitação da área de cada patologia encontrada, no formato de polígonos, o que facilitou e permitiu fazer a quantificação e o dimensionamento de cada uma. A Figura 5 mostra a imagem panorâmica do Palácio, com o mapeamento e registro das patologias encontradas.

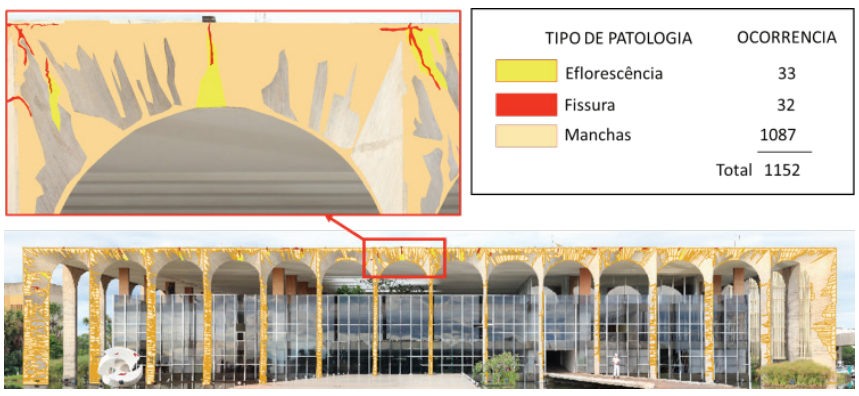

Figura 5: Identificação, mapeamento das patologias encontradas na superfície da fachada principal do Palácio Itamaraty, Brasília, DF. (CostaMS-05.jpg)

As principais patologias encontradas na superfície externa da fachada principal do Palácio foram fissuras pequenas; pequenas áreas com eflorescência e grande área com manchas claras e escuras. Como as áreas foram delimitadas através de polígonos, foi possível fazer a contagem de áreas encontradas de cada tipo de patologia, assim como, o dimensionamento de cada uma destas áreas. Foram encontradas 33 áreas com eflorescência, 32 áreas com fissuras e 1087 áreas com manchas.

É importante ressaltar que a identificação das patologias foi feito manualmente, porém a contagem e o dimensionamento, assim como o estatístico, foi feito automaticamente pelo software ArcGis.

A ocorrência das patologias encontradas pode ser observada através da Figura 6 onde é possível visualizar que, o maior índice de ocorrência foi de manchas, sendo que a ocorrência de eflorescências e fissuras foi bem próxima uma da outra. As manchas e as eflorescências encontradas não prejudicam estruturalmente a edificação, mas proporcionam, não só um efeito desfigurador sob o ponto de vista estético como também, podem abrir um caminho para o processo de futura degradação prejudicial à fachada da edificação.

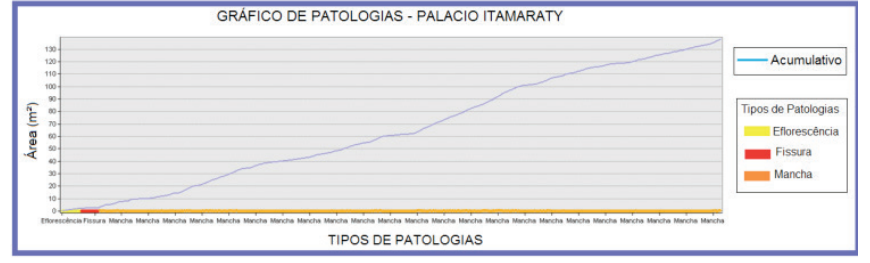

Figura 6: Ocorrência das patologias encontradas na superfície da fachada principal do Palácio Itamaraty, Brasília, DF. (Costa-MS-06.jpg)

Através deste método, também foi possível dimensionar a área de cada patologia encontrada, o que irá ajudar na tomada de decisão e nos cálculos necessários para a manutenção. A Figura 7 apresenta o gráfico de frequência de distribuição de eflorescência encontrada na superfície externa da fachada principal do Palácio, onde se tem a área, em metros quadrados, de cada polígono. E da mesma forma, pode-se determinar, também, o tamanho de cada polígono.

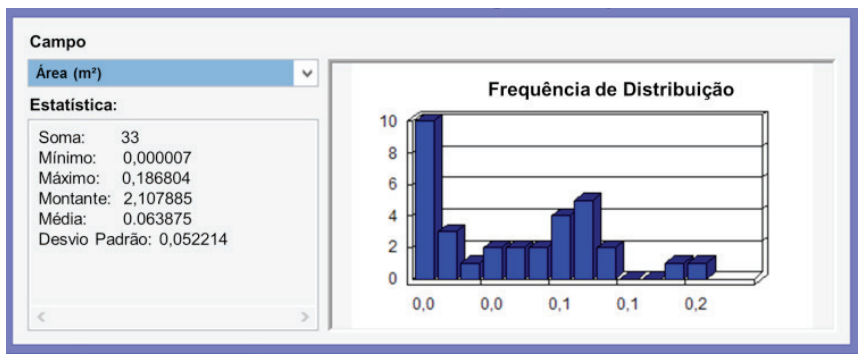

Figura 7: Gráfico da frequência de distribuição da área de cada polígono de eflorescência encontrada na superfície da fachada principal do Palácio Itamaraty, Brasília, DF.(Costa-MS-07.jpg)

Na superfície da fachada externa da fachada principal do Palácio, foram observadas 33 áreas afetadas por eflorescência, sendo que a menor área foi de 0,000007 $\mathrm{m}^{2}$ e a maior área de 0,186804 $\mathrm{m}^{2}$, chegando a um montante de $2,107885 \mathrm{~m}^{2}$. A média de ocorrência de eflorescência foi de $0,063875 \mathrm{~m}^{2}$ e o desvio padrão de 0,052214 .

Após o levantamento, a quantificação e o mapeamento dos danos encontrados, estes poderão ser registrados em fichas identificadas separadamente para cada fachada da edificação, o que permitirá ser usado como a primeira aproximação do levantamento de reparo das patologias existentes na fachada da edificação.

\section{Conclusões}

A metodologia e as ferramentas empregadas na realização do trabalho mostraram-se adequadas. Além da redução do tempo e do custo global do levantamento, foi possível realizar um registro detalhado e preciso das patologias existentes na fachada principal do Palácio Itamaraty,

No procedimento tradicional, normalmente é necessária a utilização de diversos equipamentos de apoio para identificação visual (binóculos, lunetas, etc.), assim como de equipamentos de elevação (andaimes ou rapel profissional) de pessoas para acesso a estruturas mais elevadas, ou seja, é um processo mais trabalhoso, de alto custo e arriscado em relação à segurança das pessoas envolvidas. 
Além de ser uma tecnologia de baixo custo e de fácil utilização, torna o seu emprego viável por parte dos órgãos voltados para a inspeção de edificações, permitindo assim, a obtenção de uma série de produtos de qualidade que podem ser aplicados a diversos usos, tais como o levantamento cadastral de edificações para fins de projeto de intervenção, ou ainda, a criação de acervos documentais, catálogos e inventários visando à salvaguarda ou a preservação da memória da edificação.

A metodologia desta pesquisa é válida para investigação de manifestações patológicas, mas não exime a análise da fachada danificada através de ensaios localizados e laboratoriais, além da avaliação das propriedades dos materiais, para elaboração do diagnóstico definitivo. A quantificação dos danos, por si só, não é capaz de caracterizar os mecanismos das manifestações patológicas. Ela permite direcionar o pesquisador às regiões que merecem ser avaliadas com mais detalhes.

Numa análise realizada sob o ponto de vista qualitativo, considerase que os produtos gerados atendem às necessidades usuais. E como desdobramento imediato desse trabalho está o desenvolvimento metodológico para a avaliação segura das patologias e a determinação da precisão do levantamento das mesmas.

É importante ressaltar que, um dos fatores limitantes da técnica, é a existência de obstáculos que possam limitar a visualização da fachada.

\section{Agradecimentos}

Agradecemos a CAPES pelo apoio na forma de auxílio à pesquisa e concessão de bolsas de pesquisa e à Universidade de Brasília UnB por ceder o espaço e equipamentos para o desenvolvimento da pesquisa.

\section{Referências}

Associação Brasileira de Normas Técnicas - ABNT NBR 15575: Edificações habitacionais - Desempenho - Parte 1: Requisitos gerais. Projeto de Revisão ABNT NBR 15575-1. JUL 2012.

Amorim, A.L.; Bastian, A.V. (2012). Comparação da precisão em restituições de fachada, geradas a partir de ortofotos e de fotos retificadas. Artigo apresentado no II Seminário Nacional de documentação do patrimônio arquitetônico com o uso de tecnologias digitais. Belém, PA.

Córdoba, P.A.F. (2012). Levantamento fotogramétrico de monumentos arquitetônicos para projetos de restauração - Estudo de caso: Palácio Itamaraty - Brasília, DF. Dissertação de mestrado em estruturas e construção civil submetida ao departamento de Engenharia Civil e Ambiental da Faculdade de Tecnologia da Universidade de Brasília, UNB. Brasília, DF.

Durand, F.; Joshi, N.; Cohen, M.; d'Angelo, P. (2010). Resolution Limits in Digital Photography.

Marchetti, D.A.B.; Garcia, G.J. (1977). Princípios de Fotogrametria e Fotointerpretação. Ed. Livraria Nobel S.A. São Paulo, SP.

Schorr, B. S.; Velho, L. (2010). Gigapixel Panoramas and Narratives The making of "Love Affair". Relatório Técnico do Laboratório do Instituto de Matemática Pura e Aplicada, VISGRAF. 